University of Nebraska - Lincoln

DigitalCommons@University of Nebraska - Lincoln

Faculty Publications, College of Journalism \& Journalism and Mass Communications, College Mass Communications

2018

Country reputation management: Developing a scale for measuring the reputation of four African countries in the United States

Dane M. Kiambi

Autumn Shafer

Follow this and additional works at: https://digitalcommons.unl.edu/journalismfacpub

Part of the Broadcast and Video Studies Commons, Communication Technology and New Media Commons, Journalism Studies Commons, Mass Communication Commons, Public Relations and Advertising Commons, and the Social Influence and Political Communication Commons

This Article is brought to you for free and open access by the Journalism and Mass Communications, College of at DigitalCommons@University of Nebraska - Lincoln. It has been accepted for inclusion in Faculty Publications, College of Journalism \& Mass Communications by an authorized administrator of DigitalCommons@University of Nebraska Lincoln. 


\title{
Country reputation management: Developing a scale for measuring the reputation of four African countries in the United States
}

\author{
Dane Kiambi ${ }^{1} \&$ Autumn Shafer ${ }^{2}$ \\ 1 College of Journalism and Mass Communications, University of Nebraska- \\ Lincoln, 338 Andersen Hall, P.O. Box 880443, Lincoln, NE 68588-0443, USA; \\ emaildmwirigi@hotmail.com \\ 2 School of Journalism and Communication, University of Oregon, Eugene, OR, \\ USA; email ashafer@uoregon.edu
}

\begin{abstract}
This study extends the development of country reputation measurement to other cultural contexts, specifically among sub-Saharan African countries that have shown the desire to improve their reputation in the United States and other Western nations. Although effective management of a country's reputation lies in its ability to measure the perceptions of its target publics, there is currently no established scale that can be relied upon for such measurement of sub-Saharan African countries. In this study, a confirmatory factor analysis (CFA) was conducted using second-order latent variables, and based on the goodness-of-fit indices, it was established that all four models for measuring the reputation of four countries-Angola, Ghana, Kenya, and Nigeria-met the data fit criteria, thus validating the instrument. Validation of this scale provides empirical evidence that contributes to public diplomacy and country reputation management. Because the CFA process used in this study allows for replication of measurements across independent samples, practitioners interested in measuring the reputation of sub-Saharan African countries can use this scale to evaluate the reputation of these countries across samples of interest.
\end{abstract}

Keywords: Public diplomacy, Sub-Saharan Africa, Country reputation, Scale development, Measurement

Published in Place Branding and Public Diplomacy (2018) 14:3 (August 2018), pp 175-186.

DOI 10.1057/s41254-017-0065-7

Copyright (C) 2017 Macmillan Publishers Ltd. Used by permission.

Revised \& submitted 17 May 2017; published 1 August 2017 


\section{Introduction}

The measurement and management of country reputation is a growing area of research and practice in public diplomacy. In an increasingly globalized world, reputation management is not unique to corporations; countries are also recognizing the benefits of cultivating favorable reputations among their internal and external audiences (Passow et al. 2005).

Measuring a country's reputation is one of the first steps toward effective management of its reputation (Yang et al. 2008). There are a number of reasons that a country would want to convey a better image of itself to foreign publics. In some cases, image cultivation efforts are preceded by a crisis that requires repairing a nation's image among its international publics. In other cases, countries aim at increasing foreign investments through trade, donor aid, and tourism.

According to the U.S. Department of Justice-administered Foreign Agents Registration Act (FARA), more than 20 sub-Saharan African countries have active accounts with U.S.-based public relations and lobbying agencies, having been hired to manage the reputation of these countries and allied institutions in the U.S. (U.S. Department of Justice 2017). In spite of these countries' efforts, however, there is no single instrument that can be used to measure the reputation of any of these African countries among the American public or any other foreign stakeholder group.

The goal of this study was thus to determine whether a reliable and valid multidimensional measurement of country reputation is possible in an African research context. Specifically, the study sought to create a scale for measuring the reputation of countries in sub-Saharan Africa, a region that has for years been perceived as a bastion of intermittent internal strife, bad governance, famine, poverty, and pestilence, but which has lately shown a determination to rise above such negative perceptions by embracing democracy, legal reform, global economic interconnectedness, and good governance.

Creating this scale is important and relevant to the field of public diplomacy, because scholars and practitioners of public diplomacy need such a tool to more thoroughly investigate relationships between communication and reputation. In addition, the scale that will emerge from this study can be used when studying the reputation of individual subSaharan African countries. 
Because it would be impractical to use all African countries in a single study when attempting to create an instrument for measuring the reputation of African countries in the U.S., this study focused on four sub-Saharan African countries: Angola, Ghana, Kenya, and Nigeria.

These countries were selected because each had hired U.S.-based public relations firms to manage their reputations sometime within the 5-year period 2007-2012, which was the most recent period on record at the initial planning stage for this study. The next section will review the literature on public diplomacy and country reputation.

\section{Literature review}

\section{Country reputation}

Cultivating and managing a favorable national and international reputation is no longer the preserve of individuals and corporations. Countries are also keen on having a good name in the world of nations, because "national reputation is unquestionably an instrument of power" (Wang 2006, p. 91).

A good or bad reputation can have significant impact on a country's international interactions and transactions. According to Jervis (1970, p. 6), reputation can be "of greater use than a significant increment of military or economic power." Reputation, therefore, can be considered a form of what Nye (2004) refers to as "soft power."

Nye (2004, p. 10) describes soft power as "the ability to get what you want through attraction rather than coercion or payment. It arises from the attractiveness of a country's culture, political ideals, and policies." Hence, one of the benefits of cultivating and managing good country reputation lies in the ability to develop and enhance a country's soft power. Country reputation can hence impact a country's ability to build coalitions with its national or international partners. Countries with a good reputation also have increased numbers in the tourism sector, which has become a major source of income for nations around the world (Stock 2009; Kiambi 2017). Countries with a good reputation are also more likely to attract direct foreign investment and a skilled workforce (Kotler and Gertner 2002), and to see an increase in the purchase of their products and services internationally, than countries with bad reputations (Stock 2009). 
The challenges and opportunities for African countries in such areas as leadership and governance, security, corruption, tribalism, human rights, legal and economic reform, poverty, disease, infrastructure, and education have dominated the coverage of Africa in U.S. media over the years. Studies have shown that U.S. news reporting on Africa has largely focused on crises, conflicts, and disaster (Weaver and Wilhoit 1981; Wilhoit and Weaver 1983). Beaudoin and Thorson's (2001) analysis of foreign news in American newspapers showed that while western Europe was portrayed as beautiful, Africa was represented as a place consumed with power issues. Golan (2008) examined the coverage of Africa by the $\mathrm{ABC}, \mathrm{CBS}, \mathrm{NBC}$, and CNN evening news programs and found that the majority of stories about African nations focused on negative issues such as conflict and disasters, both natural and man-made.

The desire by various African countries to change the dominant narrative of a troubled continent in international news has led them to engage in concerted efforts to manage their reputation not only internationally, but nationally as well. Although some African countries continue to face enormous challenges that warrant negative headlines, the perpetual negative portrayal of Africa has led to "Afropessimism," a frame of "traditional conventional wisdom that views the continent as little more than a gigantic basket case" (Gordon and Wolpe 1998, p. 49).

Effective management of country reputation is a systematic process, and one of its prerequisites is a country's ability to measure its reputation (Yang et al. 2008). The opinions regarding a country as expressed by foreign publics is one of the reliable indicators of that country's reputation (Wang 2006).

The work of measuring, cultivating, and managing a country's reputation has traditionally been the mandate of public diplomacy, defined by Tuch (1990, p. 3) as “a government's process of communicating with foreign publics in an attempt to bring about understanding for its nation's ideas and ideals, its institutions and culture, as well as its national goals and policies".

Sharp (2005, p. 106) defined public diplomacy as the "process by which direct relations are pursued with a country's people to advance the interests and extend the values of those being represented." Waller (2007, p. 19) defined it as "the art of communicating with foreign publics to influence international perceptions, attitudes and policies." These three definitions point to the principal mandate of public diplomacy 
practitioners, which can be summarized as managing the reputation of their countries among foreign publics.

Although the concept of country reputation has gained prominence in the last few years, the lack of valid instruments for evaluating country reputation presents a huge challenge to practitioners of public diplomacy. This study contributes to the literature through the development of a reliable measurement of country reputation in a sub-Saharan Africa research context.

Literature on country reputation first emerged a decade ago when Passow et al. (2005) sought to measure the concept. Using the research context of the Principality of Liechtenstein, a landlocked country in Central Europe, Passow et al. (2005) created the Fombrun-RI Country Reputation Index. This index was adapted from the Harris-Fombrun Reputation Quotient (Fombrun and Gardberg 2000) that is used to measure the reputation of corporate organizations.

Because the definition of reputation, "aggregate of stakeholders' images over time," implies a relative concept, Passow et al. (2005, p. 311) decided to also measure the reputation of competitors of the Principality of Liechtenstein in Europe. Five countries and territories similar to the principality in size and attractiveness were classified as competitors.

The Fombrun-RI Country Reputation Index that emerged from the Passow et al. (2005) study has six dimensions- emotional appeal, physical appeal, financial appeal, leadership appeal, cultural appeal, and social appeal.

Yang et al. (2008) adopted this scale to measure the reputation of South Korea in the United States, and added a "political appeal" dimension, which they conceptualized as "perceptions of the country's political status such as internal relationships, democracy, and stable political environments."

In spite of these attempts by Passow et al. (2005) and Yang et al. (2008) to quantify country reputation, the concept still suffered from a lack of clear definition. Kang and Yang (2010, p. 53) made a first attempt toward defining the concept: "Country reputation refers to perceptions of a country, shared by domestic and international public, on the basis of personal experience and information received." This definition put into perspective earlier attempts by Passow et al. (2005) and Yang et al. (2008) to quantify the concept, by measuring the perceptions of the international public regarding a foreign country on a wide range of issues. 
For the purposes of this study, country reputation is defined as "perceptions of a country over time based on direct and indirect experiences with the country as compared with its competitors" (Kiambi 2017, p. 62).

As with any organization, perceptions of the reputation of a country held by its publics are formed through direct and indirect experiences. Direct experiences are based on the personal experience or contact that the public has with a country, while indirect experiences are based on secondhand encounters.

The next section will review the literature on established standards recommended for developing a measurement scale.

\section{Scale development process}

DeVellis (2003) recommends the following steps for constructing a scale: (a) determining what one wishes to measure, (b) generating an item pool, (c) determining the format of the measure, (d) having experts review the item pool, (e) considering the inclusion of validation items, (f) administering items to a sample, (g) evaluating the items, and (h) adjusting scale length.

In determining what to measure, a researcher must clearly and thoroughly define the concept of interest based on existing theory (DeVellis 2003). According to Worthington and Whittaker (2006), it is difficult to measure a poorly defined construct, because it leads to the inclusion of items that are unrelated to the construct, while excluding those that are relevant. In this study, a thorough literature review of the concept of country reputation and related dimensions was conducted. To establish a logical connection between the concept and sub-Saharan Africa, a review was performed to examine how this African region has been represented in the American media. In addition, focus groups were conducted to establish perceptions associated with each of the four sub- Saharan African countries by the target audience.

When it comes to developing an initial pool of items, researchers must strive to write clear, concise, distinct, and readable items that reflect the purpose of the study (Anastasi 1988; DeVellis 2003). It is important to include both positively and negatively worded items so that participants are required to pay close attention to the items when responding to them, and to be sensitive to culture and gender when creating the items (Noar 2003). 
In this study, unambiguous items that reflected the purpose of the study were developed. Items for each of the ten dimensions of country reputation were designed to incorporate the name of each country in every item. For example, one of the items in the security appeal dimension that sought to establish Americans' perceptions of the relative safety and security of each country read: "Angola is a secure country; Ghana is a secure country; Kenya is a secure country; Nigeria is a secure country." Incorporating the name of each country in the item ensures clarity for the participants. To ensure that participants paid attention to the items, positively and negatively worded items were created.

Another critical step is having one or more knowledgeable people (experts) assess the items for quality on a number of different issues. Some of the main issues are whether the items have face validity and content validity. Experts can also give feedback on grammar, conciseness, reading level, and redundancy (Worthington and Whittaker 2006). According to Noar (2003), these experts can be colleagues who have knowledge of the topic of research. For this study, three faculty members at a university in the south-central U.S. reviewed the scale items for face validity and content validity.

After all of the above steps had been completed, the items generated were administered to the target population, after which they were evaluated, and an optimized scale length was determined.

The following research question guided this study: "What dimensions of country reputation constitute a reliable and valid measurement of the reputation for each of the four sub-Saharan African countries (individually - Angola, Ghana, Kenya, and Nigeria) in the United States?'

\section{Method}

\section{Measuring country reputation}

This study adopted the validated country reputation instrument from the study by Yang et al. (2008) in order to create a modified instrument for measuring the reputation of the sub-Saharan African countries in the United States. Three new dimensions were added: security appeal, people appeal, and sports appeal were added to the adopted Yang et al. (2008) scale. 
These three dimensions were added after an analysis of the most frequently occurring themes from three focus groups conducted by the researchers. Each group had 6-12 participants with various demographic characteristics, including age, gender, race, educational background, and level of interaction with people from any of the four sub- Saharan African countries.

Focus group protocol questions focused mainly on what came to participants' minds when each of the four countries was mentioned. Data from the focus groups showed that safety concerns related to travel to these countries was top of mind for most participants. The security concerns voiced by participants in discussing their perceptions of Angola, Nigeria, Ghana, and Kenya are reflected in the coverage of Africa in U.S. media, which according to Golan (2008), focuses mostly on conflicts and disasters.

In the face of international disasters such as health scares and terrorist attacks, Coaffee and Rogers (2008) use the concept of reputational risk to argue that "security" has become a key selling point of city branding: "Security and emergency preparedness are increasingly becoming affiliated with branding practices and utilized by governance regimes to promote and brand particular locales as safe, secure and resilient to attack" (Coaffee and Rogers 2008, p. 205).

Another recurring theme was the ability of people from each of the four countries to live peacefully side by side. As one participant observed, "There are those tribal groups that we read are always warring against one another over either grazing land or water. It raises questions of whether they will ever live in peace with each other."

The U.S. media have consistently reported on the conflicts, large or small. Foreign Policy magazine noted that, by 2010, "nearly half of the continent's 53 countries [were] home to an active conflict or a recently ended one. Quiet places such as Tanzania [were] the lonely exceptions; even user-friendly, tourist-filled Kenya blew up in 2008" (Gettleman 2017).

A third prominent theme arising from focus group discussions was the competitive nature of athletes and sporting teams from the four African countries on the world stage.

The recurrence of the three themes from the focus group data led the researchers to conceptualize and measure them as stand-alone dimensions. These were incorporated into the study along with the seven dimensions-emotional, physical, financial, leadership, cultural, global, 
and political appeal-used by Yang et al. (2008) to measure the reputation of South Korea. The items used by Yang et al. were modified to reflect the cultural context of the present study, thus extending these seven dimensions to the study of sub-Saharan Africa. A definition of each of the ten dimensions as conceptualized for the purposes of this study is offered next, along with the items, mean scores, standard deviations, and reliability measures from each of the ten dimensions.

\section{Dimensions of sub-Saharan African countries' reputation scale}

The following dimensions were used to measure the country reputation of each of the four sub-Saharan African countries. The items were measured on a six-point Likert-type scale from strongly disagree (1) to strongly agree (6).

\section{Security appeal}

This dimension refers to perceptions of a country as capable of providing security to its people and visitors. Kenya continues to face internal and external security threats arising from militant groups from neighboring Somalia. These threats have been visited on American and British tourists inside Kenya, which have been widely reported in the U.S. media. Such incidents have no doubt influenced Americans' perceptions of Kenya's ability or inability to oversee the security of its citizens and visitors. Nigeria has been rocked by waves of violence perpetrated by an internal radical Muslim group bent on creating an Islamic state within the country. Quoting the Human Rights Watch advocacy organization, The New York Times reports that over 2800 have died since 2009 in attacks targeting places of worship (2012, p. A8).

The items that measured this dimension for each of the four countries were as follows: "This country is a secure place"; "This country is capable of protecting its people"; "This country is capable of protecting its visitors/tourists"; "The security apparatus of this country is capable of meeting internal and external security threats." The following are the mean, standard deviation, and reliability of this dimension for each of the four countries: Angola $(M=2.80, \mathrm{SD}=1.04, \alpha=0.96)$; Ghana $(M=$ $3.12, \mathrm{SD}=1.07, \alpha=0.95)$; Kenya $(M=3.54, \mathrm{SD}=1.16, \alpha=0.96)$; Nigeria $(M=2.88, \mathrm{SD}=1.21, \alpha=0.96)$. 


\section{People appeal}

This dimension refers to the perception of a country's people as peaceful and capable of living in peace, not only amongst themselves, but also with foreigners. The postelection violence of 2007-2008, when Kenyans turned against one another, was very damaging to their reputation as a peaceful people. Mass media images of dead bodies, badly injured people, machete-wielding protestors, burning houses, and looting of property made headlines in the U.S. media, and may have created certain perceptions of Kenya and its people in the minds of the American public. A repeat of such murderous incidents in 2012, when over 100 people died in Kenya's southern region, could have reaffirmed Americans' perceptions of Kenyans as a violent people. In Nigeria, thousands have lost their lives to terrorist attacks by an internal radical Muslim group seeking to create an Islamic state within its borders, as mentioned above. Images of the dead following the attacks have been broadcast around the world. Media images from the over-two-decades-long civil war in Angola, which ended in 2002, could remain etched in the minds of many foreigners for some time. Of the three countries, only Ghana has not witnessed any internal or external threats to peace.

The people appeal dimension was measured using the following items: "The people of this country are capable of living peacefully among themselves"; "The people of this country are warm and welcoming"; "The people of this country can tolerate one another"; "The citizens of this country respect the rule of law"; "The citizens of this country are a peaceful people." The following are the means, standard deviations, and reliability values for this dimension: Angola $(M=3.50, \mathrm{SD}=0.96$, $\alpha=0.94)$; Ghana $(M=3.81, \mathrm{SD}=0.93, \alpha=0.95)$; Kenya $(M=4.02, \mathrm{SD}=$ 1.02, $\alpha=0.90)$; Nigeria $(M=3.47, \mathrm{SD}=1.09, \alpha=0.94)$.

\section{Sports appeal}

This dimension refers to the competitiveness of a country in the international sports arena. Over the years, Kenyan athletes have stood out as some of the most competitive runners in medium- and long-distance races held in various places around the world. Kenyan men and women athletes have been winners in the Boston Marathon many times since 1991. In the Chicago Marathon, Kenyan male runners held first place 
uninterrupted from 2003 through 2011. These victories shine a spotlight on the country and perhaps engender positive perceptions of the country and its people. Nigeria, Ghana, and Angola have also recorded sports successes, albeit not in medium- or long-distance races like Kenya. Nigeria and Ghana have qualified more than once to take part in the FIFA World Cup tournament, an event that is watched by billions of people around the world, and Angola's soccer team qualified for the 2006 FIFA World Cup.

The sports appeal dimension was measured using the following items: "The sportsmen and -women of this country are competitive"; "This country has a distinct sporting culture"; "The sportsmen and women of this country are admirable"; "I admire the competitiveness of this country's sportsmen and -women"; "I admire this country's sporting culture." The following are the means, standard deviations, and reliability values for the sports dimension: Angola $(M=3.34, \mathrm{SD}=0.97, \alpha=0.94)$; Ghana $(M=3.65, \mathrm{SD}=0.99, \alpha=0.95)$; Kenya $(M=4.35, \mathrm{SD}=1.15, \alpha=0.97)$; Nigeria $(M=3.65, \mathrm{SD}=0.99, \alpha=0.97)$.

\section{Emotional appeal}

This dimension refers to the extent to which a country is liked, respected, and admired by others. The following items, which were adopted from Yang et al. (2008), were used to measure the emotional appeal of the four African countries: "I respect this country"; "I like this country"; "I trust this country"; "I admire this country." The following are the means, standard deviations, and reliability values for the emotional appeal dimension: Angola $(M=3.17, \mathrm{SD}=0.99, \alpha=0.93)$; Ghana $(M=3.48, \mathrm{SD}=$ $1.03, \alpha=0.93)$; Kenya $(M=3.90, \mathrm{SD}=1.11, \alpha=0.94)$; Nigeria $(M=3.17$, $\mathrm{SD}=1.23, \alpha=0.95$ ).

\section{Physical appeal}

This dimension refers to perceptions of the country's infrastructure including health care, housing, roads, communications, and services. Passow et al. (2005) and Yang et al. (2008) operationalized this dimension with the following three items: "This country is a beautiful place"; "This country has well-educated residents"; "This country has a good infrastructure of roads, housing, services, health care, and communications." 
The current study, however, examined the first two items as originally written, but divided the infrastructure item into four separate items, as follows: "This country has good roads"; "This country has good health care"; "This country has good communication services"; "This country has good housing."

Breaking down the infrastructure item into four separate items would appear to be consistent with how sub-Saharan Africa has been represented in the media for decades. Reports abound on the region as lacking in health care, good roads, and housing, among other needs. Advocacy organizations such as the United Nations Development Program (UNDP) and the Bill \& Melinda Gates Foundation have devoted enormous time and resources in trying to address challenges in health care and housing in sub-Saharan Africa.

An examination of the six items (i.e., beautiful, well-educated, and four infrastructure items) showed that the item "This country is a beautiful place" produced low reliability for the scales of the four countries and was thus excluded from the analysis. The five remaining items were used to create composites for the dimension, and the following are the mean, standard deviation, and reliability of the physical appeal dimension for each country: Angola $(M=2.75, \mathrm{SD}=0.92, \alpha=0.94)$; Ghana $(M$ $=2.93, \mathrm{SD}=0.96, \alpha=0.91)$; Kenya $(M=3.32$, $\mathrm{SD}=1.03, \alpha=0.95)$; Nigeria $(M=2.98, \mathrm{SD}=1.09, \alpha=0.92)$.

\section{Financial/economical appeal}

According to Yang et al. (2008, p. 424), this dimension refers to "perceptions of the country's competitiveness, profitability, growth prospects, and risk of investment." The following items were used to measure the countries' financial/economic appeal: "This country is an inviting place to do business"; "This country has a well-developed industrial sector"; "This country is a low-tax country"; "This country is a safe place in which to invest"; "This country maintains a stable economic environment"; "This country is an economically advanced country."

The item "This country is a low-tax country" produced low reliability measures for the dimension's scale in each of the four countries and was thus excluded from the analysis. The five remaining items were used to create composites for the dimension in each of the four countries. The following are the means, standard deviations, and reliability values for 
the financial appeal dimension: Angola $(M=2.63, \mathrm{SD}=0.94, \alpha=0.94)$; Ghana $(M=2.84, \mathrm{SD}=0.99, \alpha=0.91)$; Kenya $(M=3.31, \mathrm{SD}=1.07, \alpha=$ $0.95)$; Nigeria $(M=2.81, \mathrm{SD}=1.17, \alpha=0.92)$.

\section{Leadership appeal}

This dimension refers to the strength of a country's leadership and the ability to communicate a vision for the country. This dimension was measured using the following four items: "This country has charismatic leaders"; "This country communicates an appealing vision of the country"; "This country is well-managed"; "This country upholds international laws." The following are the means, standard deviations, and reliability values for the leadership appeal dimension: Angola $(M=3.02, \mathrm{SD}=0.95$, $\alpha=0.91)$; Ghana $(M=3.31, \mathrm{SD}=0.99, \alpha=0.91)$; Kenya $(M=3.74, \mathrm{SD}=$ 1.04, $\alpha=0.92)$; Nigeria $(M=3.06, \mathrm{SD}=1.13, \alpha=0.93)$.

\section{Cultural appeal}

According to Yang et al. (2008), cultural appeal refers to the country's distinct values and historical past. It was measured using the following items: "This country is socially and culturally diverse"; "This country offers enjoyable entertainment activities"; "This country has distinct culture"; "This country has an appealing culture"; "This country has appealing food."

The item "This country has distinct culture" produced low reliability for the scales of each of the four countries and was consequently excluded from the analysis. The following are the means, standard deviations, and reliability values for the cultural appeal dimension: Angola $(M$ $=3.39, \mathrm{SD}=0.97, \alpha=0.90)$; Ghana $(M=3.64, \mathrm{SD}=1.03, \alpha=0.88)$; Kenya $(M=4.17, \mathrm{SD}=1.04, \alpha=0.90)$; Nigeria $(M=3.62, \mathrm{SD}=1.09, \alpha=0.90)$.

\section{Social/global appeal}

Yang et al. (2008, p. 425) indicate that this dimension refers to perceptions of a country's high standards in "its dealings with global community, good causes, and environmental policies." The dimension was measured using the following items: "This country supports good causes"; "This country is a responsible member of the global community"; "This 
country supports responsible environmental policies"; "This country actively participates in world affairs"; "This country is very open to foreign countries." The following are the means, standard deviations, and reliability values for the global appeal dimension: Angola $(M=3.10, \mathrm{SD}$ $=0.93, \alpha=0.94)$; Ghana $(M=3.39, \mathrm{SD}=0.93, \alpha=0.93)$; Kenya $(M=3.77$, $\mathrm{SD}=1.03, \alpha=0.95)$; Nigeria $(M=3.77, \mathrm{SD}=1.03, \alpha=0.94)$.

\section{Political appeal}

Yang et al. (2008, p. 425) defined political appeal as a country's "political status such as internal relationships, democracy, and stable political environments." The dimension was measured using the following items: "This country maintains good international relationships with U.S."; "This country maintains good international relationships with its neighbors"; "This country is a democratic country"; "This country maintains a stable political environment"; "This country respects the rule of law." The following are the means, standard deviations, and reliability values for the political appeal dimension: Angola $(M=3.16, \mathrm{SD}=0.90$, $\alpha=0.92)$; Ghana $(M=3.52, \mathrm{SD}=0.94, \alpha=0.93)$; Kenya $(M=3.85, \mathrm{SD}=$ $1.03, \alpha=0.95)$; Nigeria $(M=3.85, \mathrm{SD}=1.03, \alpha=0.94)$.

\section{Study sample}

An online survey mode was used to collect data from citizens of the United States $(N=465)$ who were 18 years of age and older, and had a prior direct or indirect interaction with people or information from any of the four sub-Saharan African countries. The sample comprised individuals with heterogeneous demographic characteristics in terms of age ( median $=34, \mathrm{SD}=12.86)$, gender (female $=53.3 \%$, ale $=46.7 \%$ ), ethnicity (Asian/Pacific Islander $=5.8 \%$, black/African American $=9.2 \%$, Hispanic $/$ Latino $=4.7 \%$, Native American $/$ American Indian $=1.1 \%$, white Caucasian $=76.8 \%$, other $=2.4 \%$ ), educational level (bachelor's degree $=35.1 \%$, college credit $=25.4 \%$, associate's degree $=12 \%$, master's degree $=11 \%$ ), employment status (employed for wages $=49.5 \%$, self-employed $=20.6 \%$ ), and income level (median of between $\$ 30,000$ and $\$ 60,000)$.

Participants were drawn from 40 U.S. states. To reach a diverse number of Americans, data were collected through Mechanical Turk (MTurk), 
a data collection website hosted by Amazon. The participant group was both a convenience and purposive sample-convenience because the pool of participants was selected based on availability to the researchers, and purposive because the researchers concluded that some participants were more relevant to the study based on their prior direct or indirect interaction with people or information from any of the four countries. Each participant was paid $\$ 0.80$ for the study, which took approximately $30 \mathrm{~min}$ to complete.

\section{Data analysis}

Amos 6.0 software was used to analyze data for the hypothesized confirmatory factor analysis (CFA) and structural equation models. To answer the research question, which sought to establish the dimensions of country reputation that constituted a reliable and valid measurement of reputation for each of the four African countries, the researchers conducted a two-step CFA process.

While techniques such as principal component analysis (PCA) and factor analysis have been used previously in scale development, CFA has in recent years taken on a major role in scale development, with a cross-section of scholars preferring CFA over either PCA or factor analysis. Velicer et al. (1994), Rubio et al. (2001), and Noar (2003) have endorsed the use of CFA in scale development because of its ability to provide additional information about the dimensionality of a scale. In this one-sample study, a within-group CFA procedure was used to test different hypothesized factor structures across four African countries. The results provide interesting observations on how well the data fit the hypothesized structure in each of the countries.

\section{Procedure}

In answering the research question, a two-step CFA process was used. First, CFA was conducted using the hypothesized second-order latent variables of the measured variables in each of the four countries. This was followed by an assessment of data-model fit criteria between the models of each of the four countries. According to Kline (1998), a model can be considered valid when the value of the chi-square/ $d f$ ratio is less than 3 , the value of comparative fit index (CFI) is equal to or greater 
than 0.95 , and the value of the root mean square error of approximation (RMSEA) is less than 0.08. The chi-square/ $d f$ ratio and RMSEA are parsimonious fit indices. The CFI, which according to Byrne (1994) can also have acceptable values greater than 0.90 , is used to compare the hypothesized model against the initial (null) model.

The Akaike information criterion (AIC), as a parsimonious fit index, is used to provide information on which model among the equivalent models (in this case among the four models of the four countries) has the best data- model fit. According to Byrne (1994), a smaller AIC value signifies a better data-model fit. Once it was established which data model among the four countries was the best fit for the criteria, the second step of creating a one-factor model was initiated. The one-factor model was used for comparison with the second-order latent variable model (hierarchical model) which, according to Noar (2003), is usually retained as the model of best fit based on the principle of parsimony.

The two-step CFA process is critical in establishing the dimensionality of this study's country reputation scale. First, the second-order (hierarchical) latent model tests the assumption that the ten dimensions (factors) of country reputation are related to one another. It also tests whether all the factors are related to a higher order, and support for this model would indicate that it would be appropriate to sum up the total scale.

Second, the one-factor model, which is tested against the second-order latent model, assesses whether the country reputation scale is measuring one overall factor in each of the countries instead of ten different factors. Support for the one-factor model implies that participants in the study did not differentiate among the ten dimensions of country reputation as stipulated in the literature, and that country reputation was best represented by a single construct. A comparison of these two modelshierarchical and one-factor-thus offers additional information on the scale and furthering of theory.

However, before conducting a comparison between the second-order and one-factor models, another critical analysis was conducted to test whether there was a significant chi-square difference between the model with fewer parameters and the model with added parameters in the second-order model category. 


\section{Results and findings}

The research question sought to establish the dimensions of country reputation that constitute a reliable and valid measure of reputation for each of the four sub-Saharan African countries. Figure 1 shows the hypothesized second- order factor model of country reputation that was used for each of the four countries.

The results of the hypothesized second-order factor models for each of the four countries were assessed using the data fit criteria as outlined by Kline (1998) and Byrne (1998) with regard to data-model fit (see Table 1 for a comparison of model fit among the four countries).

Based on the goodness-of-fit indices of the CFA conducted using second-order latent variables, all four models of the four countries met the data fit criteria. A significant chi-square test statistic is indicative of poor

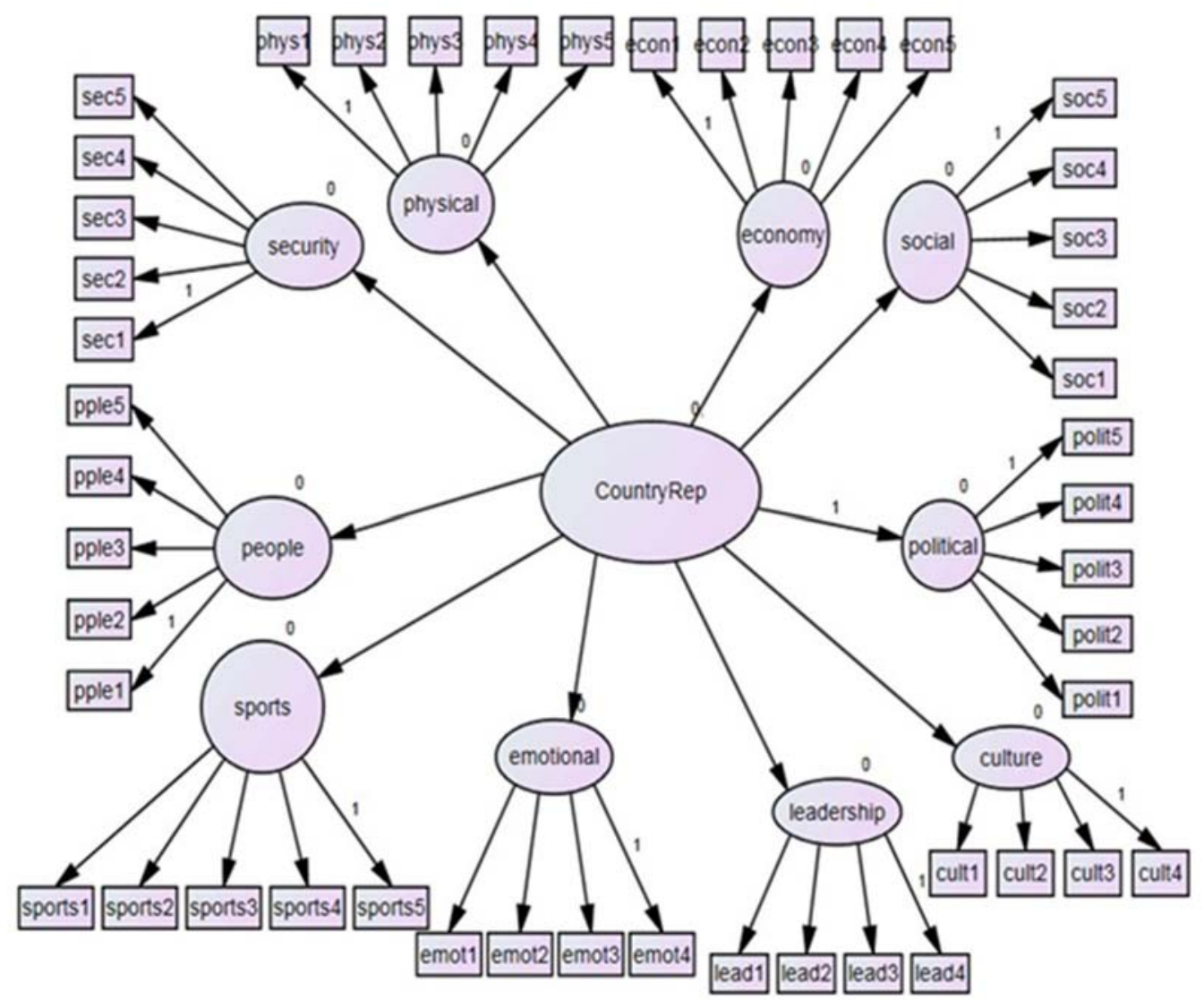

Fig. 1. Hypothesized second-order model of country reputation for each of the four countries 
Table 1. Model comparisons: goodness-of-fit indices

\begin{tabular}{lrrrrrr}
$\begin{array}{l}\text { CFA models } \\
\text { of country } \\
\text { reputation }\end{array}$ & $d f$ & $\chi^{2}$ & $\begin{array}{r}\chi^{2} / d f \\
(<3)\end{array}$ & $\begin{array}{r}\text { CFI } \\
(>0.90)\end{array}$ & AIC & $\begin{array}{r}\text { RMSEA } \\
(<0.08)\end{array}$ \\
\hline Angola & 1024 & $2404.76^{* * *}$ & 2.35 & 0.94 & 2706.76 & 0.05 \\
Ghana & 1024 & $2610.21^{* * *}$ & 2.57 & 0.93 & 2926.21 & 0.06 \\
Kenya & 1024 & $2746.37^{* * *}$ & 2.69 & 0.94 & 3055.54 & 0.06 \\
Nigeria & 1024 & $2975.38^{* * *}$ & 2.93 & 0.93 & 3297.38 & 0.06 \\
\hline
\end{tabular}

CFI comparative fit index, AIC Akaike information criterion, RMSEA root mean square error of approximation. According to Byrne (1994) and Kline (1998), a model can be considered valid when the value of $\chi^{2} / d f$ is less than 3 , the value of CFI is equal to or greater than 0.90 , and the value of RMSEA is less than 0.08 .

*** A significant chi-square test is indicative of poor model fit, and according to Kline (1998), chi-square is usually significant with a large sample, and in such circumstances the CFI and RMSEA provide a better measure of fit.

model fit, and according to Kline (1998), chi-square is usually significant with a large sample, and in such circumstances the CFI and RMSEA provide a better measure of fit.

With regard to the research question, the researchers can thus conclude that all ten dimensions of country reputation constitute a reliable and valid measurement of reputation for each of the four countries. These dimensions are security appeal, people appeal, sports appeal, emotional appeal, physical appeal, financial appeal, leadership appeal, cultural appeal, social appeal, and political appeal.

Additional information about the best data-model fit among the four countries can be obtained, however, by looking at the AIC. The model with the smallest AIC value is that of Angola (AIC $=2704.76$ ), thus qualifying it as the best data-model fit.

In addition to the AIC, further analysis was conducted to determine whether there was a significant chi-square difference between the model with fewer parameters and the model with added parameters in the Angola second-order model.

The results showed that the alternative model with added paths had better model fit, with chi-square of 2404.76 and 1024 degrees of freedom $\left(\chi^{2}=2404.76, d f=1024, p<0.001\right)$, compared to chi-square of 2578.57 and 1025 degrees of freedom $\left(\chi^{2}=2578.57, d f=1025, p<0.001\right)$ for the model with fewer paths. The difference in the chi-square number between the two models is 173.81 , while the difference in the degrees of 
Table 2. Differences in chi-square between the alternative model with added paths and the model with fewer paths

\begin{tabular}{lrrrrrrr}
$\begin{array}{l}\text { Angola second-order } \\
\text { model }\end{array}$ & $\chi^{2}$ test & & & \multicolumn{4}{c}{ Change in $\chi^{2}$ test } \\
\cline { 6 - 8 } & $\chi^{2}$ & $d f$ & $P_{c}$ & $\chi^{2}$ & $d f$ & $P_{c}$ \\
\hline $\begin{array}{l}\text { Model with fewer } \\
\text { parameters }\end{array}$ & 2578.57 & 1025 & $<0.001$ & - & - & - \\
$\begin{array}{c}\text { Model with added } \\
\text { parameters }\end{array}$ & 2404.76 & 1024 & $<0.001$ & 173.81 & 1 & $<0.001$ \\
\hline
\end{tabular}

freedom is 1; hence the decision to adopt the alternative model. Table 2 shows the differences in chi-square between the two models.

After establishing that the Angola second-order model had the best data-model fit because it had the smallest AIC and a significantly reduced chi-square, the second step in creating a one-factor model using data on Angola was initiated. This step uses only the Angola model data because it is meant to confirm that a second-order latent model provides a better fit than a one-factor model, an issue that is widely recognized in the literature (Noar 2003; Rubio et al. 2001). The one-factor model was used for comparison with the second-order latent variable model which, according to Noar (2003), is usually retained as the model of best fit based on the principle of parsimony.

Results of the one-factor model for Angola were as follows: $d f=1034$; $\chi^{2}=7811.24 ; \chi^{2} / d f=7.55 ; \mathrm{CFI}=0.71 ;$ and RMSEA $=0.12$. Based on the goodness-of-fit indices, the one-factor model represents a poor fit of the data. The researchers can, therefore, retain the second-order (hierarchical) latent variable model as the best fit model. Table 3 summarizes the results of the comparison of the two models on Angola.

Based on the principle of parsimony, as well as previous research and theory, the second-order (hierarchical) latent model was retained as the model of best fit. Retention of the hierarchical model is significant, because it indicates that each of the ten dimensions of country reputation

Table 3. Angola one-factor and second-order model comparisons

\begin{tabular}{lcccccc} 
Models & df & $\chi^{2}$ & $\begin{array}{c}\chi^{2} / d f \\
(<3)\end{array}$ & $\begin{array}{c}\text { CFI } \\
(>0.90)\end{array}$ & AIC & $\begin{array}{c}\text { RMSEA } \\
(<0.08)\end{array}$ \\
\hline Angola second-order & 1024 & $2404.76^{* * *}$ & 2.35 & 0.94 & 2706.76 & 0.05 \\
Angola one-factor & 1034 & $7811.24^{* * *}$ & 7.55 & 0.71 & 7999.24 & 0.12 \\
\hline
\end{tabular}


are first-order factors that are related to a second-order factor termed "country reputation," as the literature shows.

The standardized factor loadings of items from each of the four African countries were assessed, and items with loadings of less than 0.50 were removed from the analysis. Cohen (1988) described guidelines for interpreting effect size of correlations in the social sciences as follows: (a) small effects: coefficients with values less than 0.10; (b) medium effects: coefficients with values around 0.30; and (c) large effects: coefficients with values of 0.50 and above.

One item was removed from each of the following four dimensions across the four countries: people appeal, physical appeal, cultural appeal, and economic/financial appeal. Items and dimensions included in the final analysis were the same across the four countries.

Table 4 shows the standardized factor loadings of the ten latent variables of country reputation for each of the four sub-Saharan African countries, along with construct reliability and construct validity.

\section{Validity and reliability of the scale}

After face and content validity have been satisfied during the initial development of scale items, researchers have noted that the next most

Table 4. Standardized factor loadings for ten latent variables of each of the four subSaharan African countries, construct reliability, and construct validity

\begin{tabular}{lcccc} 
Latent variables & \multicolumn{3}{c}{ Sub-Saharan African countries } \\
\cline { 2 - 5 } & Angola & Ghana & Kenya & Nigeria \\
\hline Security appeal & 0.90 & 0.87 & 0.88 & 0.92 \\
People appeal & 0.83 & 0.80 & 0.89 & 0.84 \\
Sports appeal & 0.59 & 0.62 & 0.59 & 0.62 \\
Emotional appeal & 0.83 & 0.85 & 0.87 & 0.90 \\
Physical appeal & 0.89 & 0.85 & 0.84 & 0.87 \\
Financial appeal & 0.88 & 0.88 & 0.86 & 0.89 \\
Leadership appeal & 0.94 & 0.94 & 0.98 & 0.97 \\
Cultural appeal & 0.78 & 0.81 & 0.82 & 0.79 \\
Social appeal & 0.91 & 0.91 & 0.94 & 0.93 \\
Political appeal & 0.90 & 0.90 & 0.93 & 0.95 \\
Construct reliability: coefficient $\mathrm{H}>0.90$ & 0.95 & 0.95 & 0.96 & 0.93 \\
Construct validity: variance extracted $>0.50$ & 0.72 & 0.71 & 0.75 & 0.76
\end{tabular}

The cut-off construct reliability value for a good scale is 0.90 . Variance extracted, as construct validity (i.e., average standardized loadings), is acceptable if it exceeds 0.50 
important type of validity that should concern scale developers is construct validity. Construct validity refers to whether the scale is measuring what a researcher thinks it is measuring (Noar 2003). Two types of validity that are subsumed under construct validity are convergent and divergent/discriminant validity (Anastasi 1988).

Convergent validity illustrates how well the item measures relate to one another with respect to a common construct, and is indicated by high factor loadings of measures on hypothesized constructs (Anderson and Gerbing 1988; Swafford et al. 2006). In the current study, only items with high factor loadings were retained for analysis. Therefore, convergent validity of country reputation scales for the four African countries was established.

Discriminant validity is able to show the researcher that items that should not be related are in fact not related (Anastasi 1988). In this study, items with insignificant factor loadings of less than 0.40 were removed from the analysis. Thus the discriminant validity of the scale was established by removing from the analysis items that discriminated from one another.

Convergent validity was also established through the construct validity statistic (variance extracted), as shown in Table 3. Extracted variance is the average squared standardized factor loadings of the indicators of a given latent variable (Yang 2007). Variance extracted is acceptable if it exceeds 0.50 . In this study, the construct validity of the scales used was strong across all four countries: 0.72 for Angola, 0.71 for Ghana, 0.75 for Kenya, and 0.76 for Nigeria.

The literature suggests that a measure of country reputation should be related to dimensions of physical appeal, economic/financial appeal, social/global appeal, political appeal, cultural appeal, leadership appeal, and emotional appeal. In this study, three additional appeal dimensions - security appeal, people appeal, and sports/athletics appealwere included to capture the research context of sub-Saharan Africa. The high factor loadings on all ten dimensions points to the high construct validity of the sub- Saharan Africa scale.

The predictive validity of the scale was assessed by averaging all the composites of the scale dimensions into a single composite for each county (reputation scale) and correlating each country's reputation scale with a composite of six items measuring the desire to visit, recommend, and purchase products from the country. The country desirability items were measured on a six-point Likert-type scale ranging 
from "strongly disagree to "strongly agree, and included items such as "I would recommend visiting [country] to others" and "I think I would love to visit [country]." Results support moderate to high predictive validity of the reputation scale for Ghana $(r(465)=0.67, p<0.01)$, Nigeria $(r(465)=0.76, p<0.01)$, Kenya $(r(465)=0.72, p<0.01)$, and Angola $(r(465)=0.66, p<0.01)$.

Reliability was first assessed by determining the reliability of the composites of measurement items. All ten dimensions in this study had reliability of 0.80 and above. In addition, the study used Hancock's coefficient $\mathrm{H}$ which, according to Hancock and Meuller (2001), is more suitable than Cronbach's alpha for assessing the reliability of indicators in latent variables. An acceptable value of coefficient $\mathrm{H}$ is one that is greater than 0.90 . In this study, construct reliability of the country reputation scales of the four countries was 0.95 for Angola, 0.95 for Ghana, 0.96 for Kenya, and 0.93 for Nigeria. This suggests that the scales were reliable across the four countries.

\section{Theoretical and practical implications}

In seeking to determine whether a reliable and valid multidimensional measurement of country reputation is possible in a sub-Saharan Africa research context, this study extends previous research in two ways. First, it incorporates three additional dimensions - security appeal, people appeal, and sports/athletics appeal-to the analysis, with a view toward capturing the research context of these countries. Although seven other dimensions were retained from previous studies, the researchers tailored the model to sub-Saharan Africa by incorporating modified items that captured the research contexts of each country.

This study revealed useful results for the practice and study of public diplomacy. Perhaps most importantly, regarding the proposed measurement model of sub-Saharan African country reputation, the modified multidimensional model proved to be a reliable and valid measure of country reputation for Angola, Ghana, Kenya, and Nigeria among the American public. This scale can now be applied by practitioners and researchers in public diplomacy, reputation, and tourism-related fields. The scale could be used to track reputation trends over time and to better understand how positive and negative news coverage, public relations efforts, and diplomacy affect various dimensions of each country's reputation. 
The use of four countries in one study provided the researchers with an opportunity to compare CFA measurement models for each country. Some of the advantages of CFA over exploratory factor analysis were also witnessed. CFA permits the researcher to test a variety of conceptualizations of the data and to compare different models, and provides a better understanding of how items and constructs are related to one another. In addition, because it allows statistical methods of factor comparison and equivalency testing, scales emerging from the CFA process can be replicated and generalized across independent samples (Reise et al. 2000).

The support that each country's measurement models received based on the data fit criteria suggests that the scale will be a reliable and valid measure of the country reputation of sub-Saharan African countries among the American public. Because of its replicability and generalizability across independent samples, as mentioned above, this sub-Saharan African country reputation scale can be used to measure the reputation of other sub-Saharan African countries among samples obtained from the American population.

Because the scale was shown to be a reliable and valid measure of country reputation, it also provides empirical evidence that contributes to public diplomacy and the emerging concept of country reputation. The support for the measurement models across the four countries offers researchers a chance to evaluate the significance of higher-order factor analysis techniques not only in scale development, but also in theory development. The higher-order technique used in this study indicates that the country reputation factor accounts for the relations between the latent variables (the ten dimensions), thus producing a multidimensional model.

Support for the higher-order (hierarchical) model is consistent with the literature. Borrowing from corporate reputation management literature, Passow et al. (2005) showed that country reputation could be measured using the dimensions of corporate reputation, albeit with a few changes to the items. The retention of the second-order latent model in this study as the model with the best fit for the data suggests that each of the ten dimensions are first-order factors that are related to a secondorder factor known as country reputation, as supported by the literature.

Support for the one-factor model, which was tested against the secondorder model, would have suggested that participants in the study did not differentiate between the ten dimensions of country reputation, and that 
country reputation was best represented by a single construct. Support for the second-order model, however, suggests that participants recognized the differences among the ten dimensions, and that the subscales can either be examined individually or summed together into one scale.

In the future, practitioners of public diplomacy could use this scale to conduct a multidimensional evaluation of sub- Saharan African countries before embarking on reputation management campaigns. Initiating a reputation management campaign before understanding where a country stands on a wide range of issues, as demonstrated by this multidimensional country reputation scale, would not be in the best interests of the client (i.e., a foreign country).

One major limitation of this scale may be the fact that not all dimensions will be applicable to all sub-Saharan African countries. For example, the sports dimension may not apply to Mali, Chad, or Sierra Leone, or other countries whose athletes have not registered notable success in international sports. Therefore, practitioners of public diplomacy using this scale to evaluate the American public's perceptions of various countries are advised to avoid dimensions that are obviously not applicable to their country of interest.

\section{References}

Anastasi, A. 1988. Psychological testing, 6th ed. New York: Macmillan.

Anderson, J.C., and D.W. Gerbing. 1988. Structural equation modeling in practice; A review and recommended two-step approach. Psychological Bulletin 103: 411-423.

Beaudoin, C.E., and E. Thorson. 2001. LA times offered as model for foreign news coverage. Newspaper Research Journal 22 (1): 80-93.

Byrne, B.M. 1994. Structural equation modeling with EQS and EQS/Windows: Basic concepts, applications and programming. Thousand Oaks, CA: Sage.

Byrne, B.M. 1998. Structural equation modeling with lisrel, prelis, and simplis: Basic concepts, Applications and Programming. Mahwah, NJ: Lawrence Erlbaum Associates.

Coaffee, J., and P. Rogers. 2008. Reputational risk and resiliency: The branding of security in peace-making. Place Branding and Public Diplomacy 4 (3): 205-217.

Cohen, J. 1988. Statistical power analysis for the behavioral science, 2 nd ed. New York: Academic.

DeVellis, R.F. 2003. Scale development: Theory and applications, 2 nd ed. Thousand Oaks, CA: Sage.

Fombrun, C.J., and N.A. Gardberg. 2000. Who's tops in corporate reputation? Corporate Reputation Review 3: 13-17. 
Gettleman, J. 2017. Africa's forever wars. [online] Foreign Policy. http://foreignpolicy. com/2010/02/11/africas-forever-wars/ Accessed 15 May 2017.

Golan, G. 2008. Where in the world is Africa?: Predicting coverage of Africa by U.S. television networks. International Communication Gazette 70 (1): 41-57.

Gordon, D., and H. Wolpe. 1998. The other Africa: An end to Afro- Pessimism. World Policy Journal 15 (1): 49-59.

Hancock, G.R., and R.M. Mueller. 2001. Rethinking construct reliability within latent variable systems. In Structural equation modeling: Present and future-A Festschrift in honor of Karl Joreskog, ed. R. Cudeck, S. du Toit, and D. Sorbom, 195216. Lincolnwood, IL: Scientific Software International.

Jervis, R. 1970. The logic of images in international relations. Princeton, NJ: Princeton University Press.

Kang, M., and S. Yang. 2010. Comparing effects of country reputation and the overall corporate reputations of a country on international consumers' product attitudes and purchase intentions. Corporate Reputation Review 13 (1): 52-62.

Kiambi, D. 2017. The role of familiarity in shaping country reputation. In Shaping international public opinion: A model for nation branding and public diplomacy, ed. J. Fullerton, and A. Kendrick, 57-75. New York: Peter Lang.

Kline, R.B. 1998. Principles and practice of structural equation modeling. New York: Guilford.

Kotler, P., and D. Gertner. 2002. Country as a brand, product, and beyond: A place marketing and brand management perspective. Brand Management 9: 249-261.

New York Times. 2012. Attack on Nigerian church kills 8 and wounds dozens. 29 October. p. A8.

Noar, S. 2003. The role of structural equation modeling in scale development. Structural Equation Modeling: A multidisciplinary Journal 10 (4): 622-647.

Nye Jr., J.S. 2004. Soft power: The means to success in world politics. New York: Public Affairs.

Passow, T., R. Fehlmann, and H. Grahlow. 2005. Country reputation- From measurement to management: The case of Liechtenstein. Corporate Reputation Review 7 (4): 309-326.

Reise, S.P., N.G. Waller, and A.L. Comrey. 2000. Factor analysis and scale revision. Psychological Assessment 12 (3): 287-297.

Rubio, D.M., M. Berg-Weger, and S.S. Tebb. 2001. Using structural equation modeling to test for multidimensionality. Structural Equation Modeling 8: 613-626.

Sharp, P. 2005. Revolutionary states, outlaw regimes and the techniques of public diplomacy. In The new public diplomacy: Soft power in international relations, ed. J. Melissen, 106-123. New York: Palgrave Macmillan.

Stock, F. 2009. Identity, image and brand: A conceptual framework. Place Branding and Public Diplomacy 5 (2): 118-125.

Swafford, P.A., S. Ghosh, and N. Murthy. 2006. The antecedents of supply chain agility of a firm: Scale development and model testing. Journal of Operations Management 24: 170-188. 
Tuch, H. N. 1990. Communicating with the world: U.S. public diplomacy overseas. New York: St. Martin's Press.

United States Department of Justice. 2017. Active Foreign Principals. http://www. fara.gov/quick-search.html Accessed 15 January 2017.

Velicer, W.F., R.G. Laforge, D.A. Levesque, and J.L. Fava. 1994. The development and initial validation of the smoking policy inventory. Tobacco Control 3: 347-355.

Waller, J.M. (ed.). 2007. The public diplomacy reader. Washington, DC: The Institute for World Politics Press.

Wang, J. 2006. Managing national reputation and international relations in the global era: Public diplomacy revisited. Public Relations Review 32: 91-96.

Weaver, H. D., and Wilhoit, G. C., 1981. Foreign News Coverage in Two U.S. Wire Services. Journal of Communication (pre-1986), 31(2): 55.

Wilhoit, G.C., and D. Weaver. 1983. Foreign news coverage in two U.S. wire services: An update. Journal of Communication 33 (2): 132-148.

Worthington, R., and T. Whittaker. 2006. Scale development research: A content analysis and recommendations for best practices. The Counseling Psychologist 34 (6): 806-838.

Yang, S.-U. 2007. An integrated model for organization-public relational outcomes, organizational reputation, and their antecedents. Journal of Public Relations Research 19 (2): 91-121.

Yang, S., H. Shin, J. Lee, and B. Wrigley. 2008. Country reputation in multidimensions: Predictors, effects, and communication channels. Journal of Public Relations 20 (4): 421-440.

\section{The Authors}

Dane Kiambi (Ph.D., Texas Tech University) is an Assistant Professor in the College of Journalism and Mass Communications at the University of Nebraska-Lincoln. He conducts research in crisis communication/management and public diplomacy. He has taught crisis communication, international public relations, public relations strategies, and research methods in mass media.

Autumn Shafer (Ph.D., University of North Carolina at Chapel Hill) is an Assistant Professor in the College of Journalism and Communication at the University of Oregon. Her research involves the investigation of media effects and message processing. She has taught crisis communication and public relations strategies. 